\title{
Functional Activity of the Sweat Glands of the Mouse
}

\author{
Hiromu Hayashi \\ Physiological Laboratory (Prof. M. Wada), \\ Tohoku University School of Medicine, Sendai
}

\begin{abstract}
Using the iodine-starch method for visualizing sweat, the functional activity of the eccrine sweat glands of the mouse foot-pads was studied.

The sweat glands of the pad were stimulated by local injection of parasympathomimetic agents, such as acetylcholine, carbaminoylcholine, mecholyl and pilocarpine, and sympathomimetic ones, such as adrenaline, noradrenaline and isopropylnoradrenaline. In general, the parasympathomimetic agents were more effective in eliciting sweat responses than the sympathomimetic ones.

The fact that spontaneous sweating was eliminated by relatively low concentrations of atropine, but not by relatively high concentrations of dihydroergotamine suggests that the sweat glands of the plantar surface of the mouse receive a cholinergic nerve supply. Nicotine and lobeline, injected intradermally, did not provoke an axon reflex sweating.
\end{abstract}

Luchsinger ${ }^{1}$ in 1883 described that the mouse does not sweat. Römer ${ }^{2}$ in 1898 established histologically the presence of the sweat glands in the foot pads of the mouse. Later, Schiefferdecker ${ }^{3}$ presumed that the sweat glands in the foot pads of the mouse is of an eccrine type. Recently, Ninagawa ${ }^{4}$ described very shortly that spontaneous sweating on the plantar surface of mice was visualized by the iodinestarch method of Wada and Takagaki., ${ }^{5,6}$ Previously, sweat in this region was printed on film by Sivadjian and his co-workers, ${ }^{7-10}$ using the hygrophotographic technique. They demonstrated that spontaneous sweating was abolished by intraperitoneal administration of atropine..$^{7,10}$ However, our knowledge concerning the functional activity of the sweat gland in this species is still scanty.

The present investigation attempts therefore to study the activities of the sweat glands of the mouse foot from the standpoints of the comparative physiology and pharmacology.

\section{Methods}

A total of 48 mice of dd strain, mature and immature, were used. During the observations, the whole body except the hind legs was placed, under non-anesthesia, in a specially designed metal box in the prone position and the digits were tied with fine threads so as to expand the plantar surfaces, as was described in a previous paper dealing with the study of sweating in rats. ${ }^{11}$ The interdigital and metatarsal

Received for publication, February 29, 1968. 
pads of the hind feet were chosen as test areas. The sweating was visualized by the iodine-starch method of Wada and Takagaki, ${ }^{5,6}$ and observations were made under a stereomicroscope $(\times 6.3$ or $\times 10)$. Prior to the experiment, it was ascertained that the test areas had retained good ability to sweat spontaneously.

For studying blocking effect of a given agent on spontaneous sweating, it was injected subcutaneously into the pads about 2 to 5 minutes before application of the indicator materials for visualizing sweat to the test areas.

In experiments for studying sudorific effect of a given agent, the sciatic nerves were cut away under light ether anesthesia at the level of the greater trochanter about 20 to 60 minutes before the experiment, and the agent was injected subcutaneously into the test pads after ascertaining the absence of spontaneous sweating on the test areas. The duration of sweating was roughly measured by repeating the procedure for visualizing sweat.

A Pyrex glass pipette about $150 \mu$ in diameter at the tip which had been made by stretching with a glass micro-electrode puller was utilized in place of a needle for injection, because of smallness of the test pads. The pipette was connected by a short vinyl tube with a $0.25 \mathrm{ml}$ syringe fixed upon the micromanipulator, which was kept at an appropriate angle for injecting a test solution from a point of the lateral side centralwards into the subcutaneous layer of the pad.

Each test agent was dissolved in or diluted with $0.9 \% \mathrm{NaCl}$ solution at graded concentrations, and injected in a volume of about $0.003-0.001 \mathrm{ml}$ with the aid of a screw attached to the micromanipulator.

The agents used were as follows; acetylcholine chloride (Roche), acetyl- $\beta$ methylcholine chloride (Mecholyl, Merck), carbaminoylcholine chloride (Merck), pilocarpine hydrochloride (J.P.), L-adrenaline hydrochloride (Sankyo), DLnoradrenaline hydrochloride (Sankyo), DL-isopropylnoradrenaline hydrochloride (Winthrop), nicotine (Theodor Schuchardt), lobeline hydrochloride (J.P.), atropine sulfate (J.P.) and dihydroergotamine methansulfonate (Sandoz).

In addition, histological investigation of the sweat glands was made with biopsy specimens taken under ether anesthesia, which were fixed in $10 \%$ formalin, sectioned in paraffin at 10 to 15 microns, and stained with hematoxylin and eosin.

\section{Results and Discussion}

In most of the mice used, spontaneous sweating was seen not only on the 5 apical, 4 interdigital and 2 metatarsal pads, but also in the areas closely proximal to or between the grooves transverse to the axis of each digit, in parallel with their direction, and also in the areas surrounding the interdigital pads, as shown in Fig. 1. This indicates that the distribution of the sweat glands in the plantar region of the mouse differs from those of the rat, in which the sweat glands are localized only to the apical, interdigital and metatarsal pads.11,12 The sweat spots on each interdigital pad were counted as about thirty to forty and those on each apical pad were about twenty. When sweat spots produced by iodine starch reaction became larger with lapse of time, they could be identified even with the naked eye. 


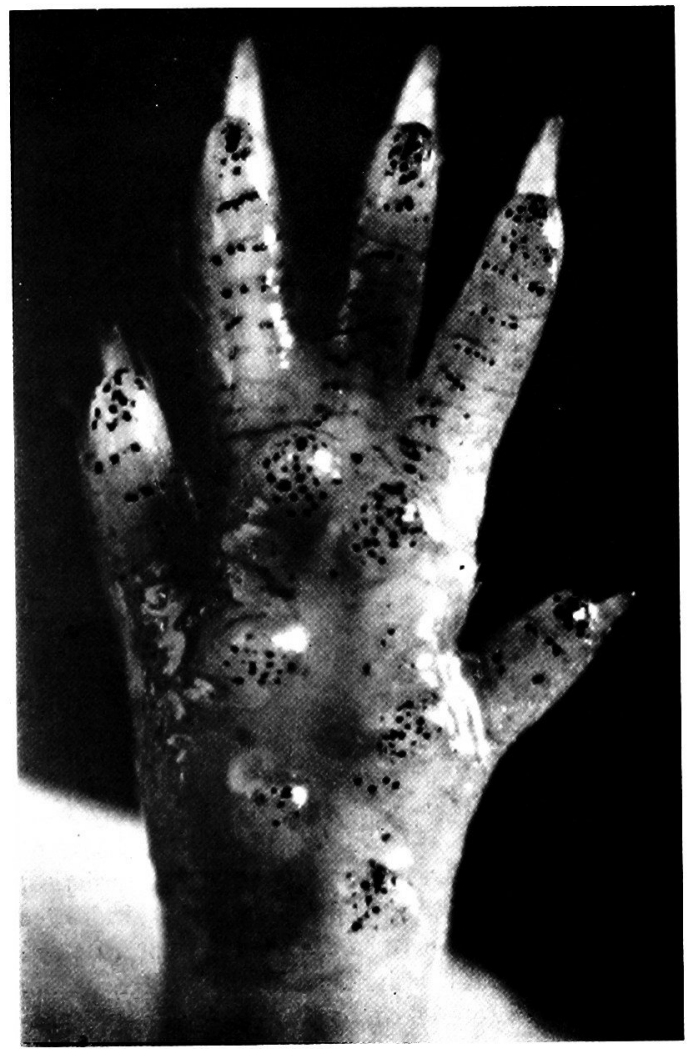

Fig. 1. Spontaneous sweating on the plantar surface of a mouse. $\times \mathbf{7 . 5}$. Unretouched.

Spontaneous sweating on the pad was uninfluenced by local injection of $0.9 \%$ $\mathrm{NaCl}$. Subcutaneous injection of atropine in $10^{-8}$ to the pads was also without effect. But a complete or almost complete inhibition of spontaneous sweating was obtained with atropine in $10^{-7}$ and $10^{-6}$. In contrast, spontaneous sweating was scarcely affected by local injections of dihydroergotamine in $10^{-6}$ and $10^{-5}$.

The threshold effective concentrations of sudorific agents were summarized in Table 1. Acetylcholine, carbaminoylcholine, mecholyl and pilocarpine were always effective in producing local sweat response, as indicated in Fig. 2. The responsiveness to these agents varied in different animals and also in different foot-pads of one and the same animals, but no significant difference was found in the sweating pattern between these four sudorific agents. In general, the response became visible on the pad within 35 to 90 seconds and ceased within about 10 minutes after the start of injection, although the latency and duration of the responses were different according to the concentrations used. At threshold effective concentrations the sweat spots appeared only on the pad injected, while at higher concentrations they appeared on and around the injected pad; and rarely the response spread to neighboring uninjected pads. It was sometimes noticed that on the test pads in which no sweat response had been seen for about 3 minutes after injection, a definite response could 
TABLE 1. The threshold effective concentrations of sudorific agents on the foot-pad of the mouse and rat

\begin{tabular}{l|c|c}
\hline & Mouse & Rat $^{*}$ \\
\hline Acetylcholine & $10^{-7}-10^{-6}$ & $10^{-7}-10^{-6}$ \\
Carbaminoylcholine & $10^{-7}$ & $10^{-8}-10^{-7}$ \\
Mecholy] & $10^{-7}-10^{-6}$ & $10^{-7}$ \\
Pilocarpine & $10^{-7}-10^{-6}$ & $10^{-6}$ \\
Adrenaline & $10^{-5}-10^{-4}$ & \\
Noradrenaline & $10^{-5}-10^{-4}$ & \\
Isopropyl-noradrenaline & $10^{-5}$ & \\
Nicotine (axon reflex) & No $\left(10^{-6}-10^{-3}\right)$ & No $\left(10^{-6}-10^{-3}\right)$ \\
Lobeline (axon reflex) & No $\left(10^{-6}-10^{-3}\right)$ & No $\left(10^{-6}-10^{-3}\right)$
\end{tabular}

No: No effect. The numerals in parentheses are the concentrations used for tests.

* The figures on the rat sweat glands are cited from the paper of Hayashi and Nakagawa"1.

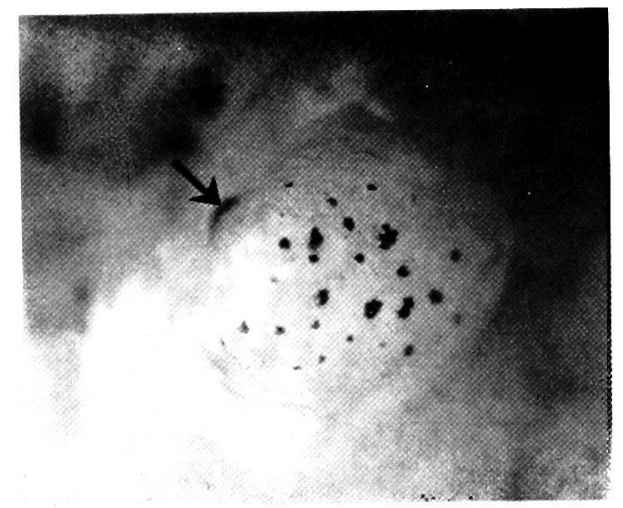

Fig. 2. Local sweating produced by subcutaneous injection of $0.002 \mathrm{ml}$ of mecholyl in $10^{-6}$ into the interdigital pad of the hind foot. Arrow indicates the site of injection. Photographed about 7 minutes after injection. $\times 20$. Unretouched.

be obtained after the re-application of the indicator materials for visualizing sweat within 5 minutes after injection. Such a response was not observed in the tests with subthreshold effective concentrations of sudorific agents or with control saline solution. Indeed, injections of $0.9 \% \mathrm{NaCl}$ solution always did not elicit any sweat response.

The sweat response to mecholyl in $5 \times 10^{-7}$ was totally abolished by atropine in $10^{-7}$ and $10^{-6}$ when applied in mixture, whereas it was unaffected by DHE in $10^{-6}$ and $10^{-5}$. The concentrations of atropine required to inhibit the sweat response to mecholyl were almost identical with those for inhibiting spontaneous sweating.

Adrenaline, noradrenaline and isopropylnoradrenaline were also found to be capable of eliciting local sweat responses. The effects of these sympathomimetic agents were more variable in different animals than those produced by parasympathomimetic agents; usually, the sweat spots produced were sparse in number and small in size, as compared with those obtained with parasympathomimetic agents. An impression was obtained that the positive results were obtained more frequently in mature animals than in immature ones. 
The fact that the parasympathomimetic agents were more effective in producing local sweat response than the sympathomimetic ones, and spontaneous sweating were selectively eliminated by relatively low concentration of atropine, but not by relatively high concentration of dihydroergotamine suggests strongly that the sweat glands of the mouse foot receive the cholinergic innervation. This is in harmony with the observation of Aoki that the sweat glands of the mouse foot pads were surrounded by cholinesterase containing nerve fibers (personal communication).

It was of interest to examine whether or not an axon reflex sweating is produced by subcutaneous injection of nicotine and lobeline to the mouse foot-pads. However, these agents in concentrations of $10^{-6}$ to $10^{-3}$ elicited no local sweat response. This finding implies that the nerve fibers supplying the mouse sweat glands lack the receptors responsible for axon reflex, like those supplying the rat foot-pads, ${ }^{11}$ in which the eccrine sweat glands receive a cholinergic nerve supply. ${ }^{13}$ In this respect the sweat nerves to the foot-pads of the mouse as well as of the rat seem to represent an exception to the conception of Wada and colleagues ${ }^{14-17}$ that the receptors responsible for axon reflex are specialized portions of the cholinergic sweat nerve endings in man and certain animals, irrespective of the type of the sweat glands. It has been shown that in the foot-pads of the cat (Wada et al. ${ }^{14}$ ) and in those of the $\operatorname{dog}\left(\right.$ Takahashi $^{18}$ ) axon reflex sweating is produced by nicotine. It may be presumed that the axon reflex mechanism is unnecessary for peripheral regulation of sweating in the rat and mouse, since the size of their foot-pads is small

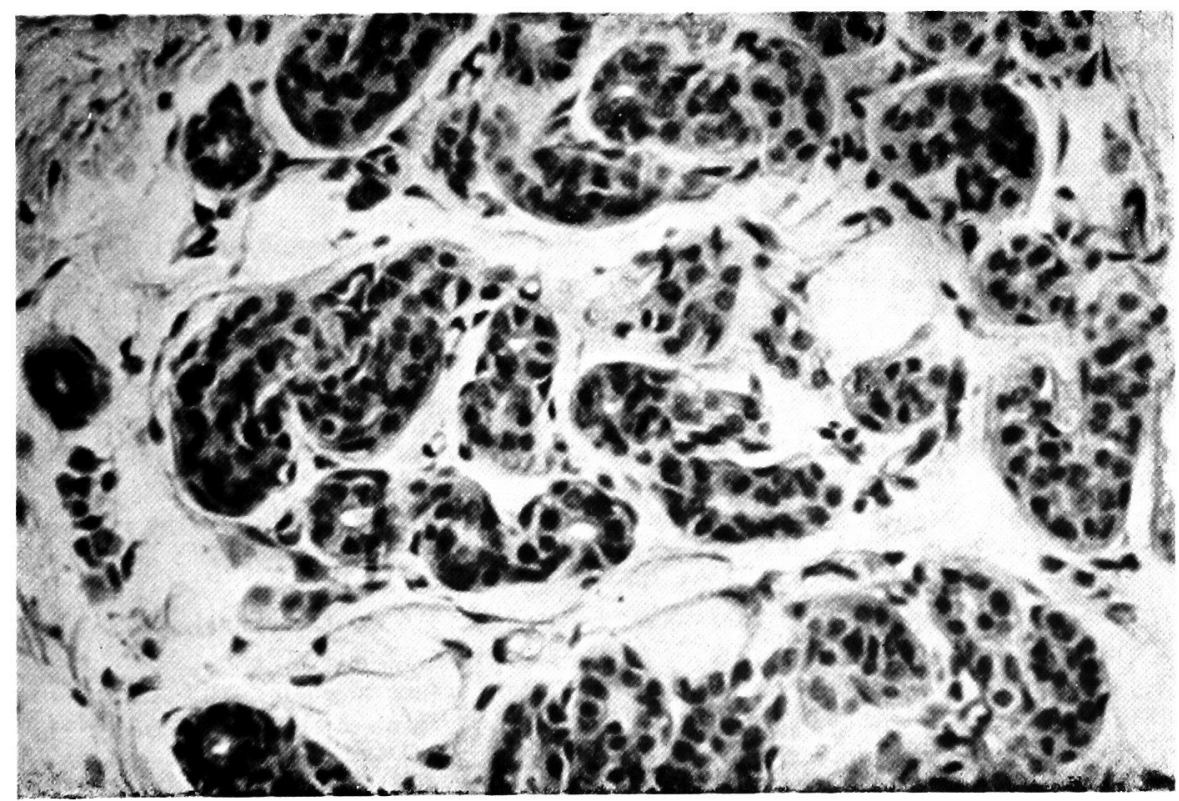

Fig. 3. Microphotograph illustrating the secretory coil of the eccrine sweat glands of the interdigital pad in a mouse. Hematoxylin-eosin. $\times 370$. 
and consequently the number of the sweat glands in each individual foot-pad is small.

In agreement with the presumption of Schiefferdecker, ${ }^{3}$ it was histologically confirmed that the sweat glands in the mouse foot-pads are eccrine in type, as illustrated in Fig. 3.

\section{Acknowledgment}

I express my thanks to Professor Masao Wada for his guidance throughout this work.

\section{References}

1) Luchsinger, B. Schweissabsonderung und einige verwandte Secretionen bei Thieren. In: Hermann's Handbuch der Physiologie, V, 1, F.C.W. Vogel, Leipzig, 1883, pp. $421-446$.

2) Römer, F. Studien über das Integment der Säugetiere. II. Das Integment der Monotremen. In: Richard Semon's zoologische Forschungsreisen in Australien und dem Malayischen Archipel, III, Jena, 1898, pp. 191-241.

3) Schiefferdecker, P. Die Hautdrüsen des Menschen und der Säugetiere, ihre biologische und rassenanatomische Bedeutung, sowie die Muscularis sexualis. Zoologica, Heft 72, E. Schweizerbart, Stuttgart, 1922.

4) Ninagawa, C. On the descending spinal pathways subserving the sweating of the plantar sweat glands in rats. Tohoku J. exp. Med., 1956, 64, 99-103.

5) Wada, M. \& Takagaki, T. A simple and accurate method for detecting the secretion of sweat. Tohoku J. exp. Med., 1948, 49, 284.

6) Wada, M. Sudorifie action of adrenalin on the human sweat glands and determination of their excitability. Science, 1950, 111, 376-377.

7) Blozovski, M. \& Sivadjian, J. Action de la sérotonine, de la réserpine et d'autres agents pharmacologiques sur la sécrétion sudorale. Études hygrophotographiques. Arch. int. Pharmacodyn., 1959, 123, 58-66.

8) Sivadjian, J. Action de la chlorpromazine sur l'épilepsie expérimentale et sur la transpiration. Arch. int. Pharmacodyn., 1963, 143, 377-384.

9) Sivadjian, J., Vautrin, M. \& Vautrin-Matge, H. Etudes neurophysiologiques sur la sécrétion sudorale. Introduction à l'hidropharmacologie. Therapie, 1965, 20, 13891402 .

10) Sivadjian, J., Vautrin, M. \& Matge, H. Studies on the cholinergic and anticholinergic effects by hygrophotographic technique. Hydropharmacology of priamide. Arch. int. Pharmacodyn., 1965, 153, 359-366.

11) Hayashi, H. \& Nakagawa, T. Functional activity of the sweat glands of the albino rat. J. invest. Derm., 1963, 41, 365-367.

12) Ring, J.R. \& Randall, W.C. The distribution and histological structure of sweat glands in the albino rat and their response to prolonged nervous stimulation. Anat. Rec., 1947, 99, 7-19.

13) Hashimoto, K., Ogawa, K. \& Lever, W.F. Histochemical studies of the skin. III. The activity of the cholinesterases during the embryonic development of the skin in the rat. $J$. invest. Derm., 1963, 40, 15-26.

14) Wada, MI. Nakamura, Y., Hatanaka, K. \& Aoki, T. On the axon reflex sweating in the toe-pads of the cat. Arch. int. Physiol., 1955, 63, 203-212.

15) Wada, M. Local sweating produced by axon reflex mechanism. In: Essential Problems in Climatic Physiology, edited by H. Yoshimura, K. Ogata and S. Itoh, Nankodo, Kyoto, Japan, 1960, pp. 185-195.

16) Wada, M., Oikawa, M., Kuribayashi, I. \& Sato, T. The effect of sodium and lithium upon the receptor for the sweating axon reflex in human skin. Arch. int. Pharmacodyn., $1962,140,606-614$ 
17) Wada, M. Comparative physiology of axon reflex sweating. Abstracts of papers, XXIII International Congress of Physiological Seiences, Tokyo, Japan, 1965, p. 301.

18) Takahashi, Y. Functional activity of the eccine sweat glands in the toe-pads of the dog. Tohoku J. exp. Med., 1964, 83, 205-219. 